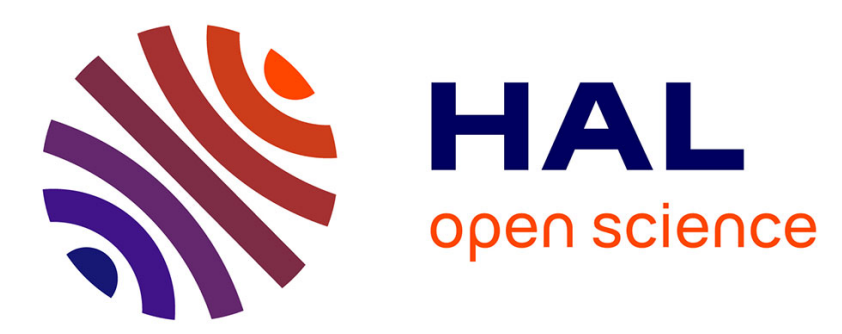

\title{
Observer-based control of a tethered wing wind power system: indoor real-time experiment
}

Ahmad Hably, Rogelio Jr Lozano, Mazen Alamir, Jonathan Dumon

\section{To cite this version:}

Ahmad Hably, Rogelio Jr Lozano, Mazen Alamir, Jonathan Dumon. Observer-based control of a tethered wing wind power system: indoor real-time experiment. ACC 2013 - American Control Conference, Jun 2013, Washington, DC, United States. Paper TuB13.2. hal-00784150

\section{HAL Id: hal-00784150 \\ https://hal.science/hal-00784150}

Submitted on 8 Jan 2014

HAL is a multi-disciplinary open access archive for the deposit and dissemination of scientific research documents, whether they are published or not. The documents may come from teaching and research institutions in France or abroad, or from public or private research centers.
L'archive ouverte pluridisciplinaire HAL, est destinée au dépôt et à la diffusion de documents scientifiques de niveau recherche, publiés ou non, émanant des établissements d'enseignement et de recherche français ou étrangers, des laboratoires publics ou privés. 


\title{
Observer-based control of a tethered wing wind power system: indoor real-time experiment
}

\author{
Ahmad HABLY, Rogelio LOZANO, Mazen ALAMIR and Jonathan DUMON
}

\begin{abstract}
High altitude wind energy (HAWE) is a new field of renewable energy that has received an increasing attention during the last decade. Many solutions were proposed to harvest this energy including the usage of kites and wings. In this paper, a novel wind power system based on a tethered wing is presented. An observer-based control strategy that avoids the need for precise knowledge of the dynamic model is then applied. Numerical simulations show the performance of the proposed control scheme which is validated in real time on an indoor experimental set-up of Gipsa-lab control system department.
\end{abstract}

\section{INTRODUCTION}

Conventional wind turbines convert wind's kinetic energy into electrical energy through a rotor coupled with an alternator. As the wind is stronger and more steady at high altitudes, the wind turbines manufacturers try to build their wind turbines as big as possible. The cost of building these wind turbines is mainly due to the cost of steel and concrete used in the construction without forgetting the complexity due to their size. The research to overcome these drawbacks has led to the birth of many airborne wind energy conversion systems (AWEC). There are 3 main types of wind energy production systems such as balloons, airborne wind turbines and finally tethered wings and kites.

The principle of the balloon developed by Magenn Power Inc. and called Magenn's Air Rotor System (MARS) is based on the rotation of a helium-filled balloon stationary at an altitude between $200 \mathrm{~m}$ to $350 \mathrm{~m}$ around a horizontal axis connected to an electrical machine. The produced energy is then transmitted to the ground by a conductive cable. The second solution studied by several companies such as Sky WindPower, Joby energy [8] or Makani Power [9], is composed of one or several airborne wind turbines to harvest energy directly in high-altitude winds and send it to the ground through conductive tethers. A third solution is to use power kites as renewable energy generators [3]. One can cite the "Kite Wind Generator" of Politecnico di Torino [6], [5] and the "Laddermill" of the Delft University of Technology [13]. These constructions have the same operation principle, which is to make the kite fly following a periodic trajectory (circular or figure-eight shape) that produces a positive amount of energy. As the kite moves upwards pulled by the wind, the dynamo generates power. When the kite is moving upwards, the wing's angle of attack is kept at a great value in order to produce a high lift force. During the phase when

with the CNRS-University of Grenoble, Control Systems Dept. Rue de la Houille Blanche, Domaine Universitaire, Saint Martin d'Heres, France ahmad.hably,(rogelio.lozano,mazen.alamir,jonathan.dumon)@gipsalab.grenoble-inp.fr the kite is moving downwards the angle of attack is chosen in a way such that almost no energy is consumed bringing back the kite to its lowest altitude. As a consequence, there will be a positive amount of energy generated at the end of each cycle.

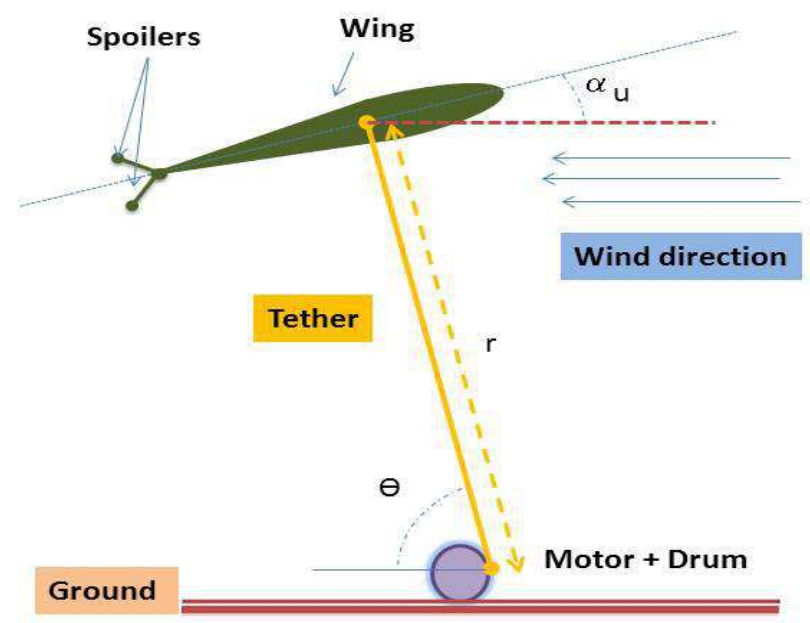

Fig. 1. The whole wind power system (wing+tether+motor) in the airflow.

Developing control strategies that enable the kite-based wind power systems to operate autonomously is a crucial issue. Indeed a kite or a wing subject to wind and attached to the ground with a rope may produce oscillations which might lead to crash. Nonlinear model predictive control (NMPC) has been applied in ([10], [5], [2]. Trajectory tracking methods including neural network control [7], robust control [12], direct-inverse control [11], and nonlinear adaptive tracking control [4] has been also proposed.

In this paper, we propose a novel wind power system similar to the third solution mentioned above but instead of using kites, a tethered light yet robust wing is used to turn a motor with the rope. An observer-based control strategy is employed. The observer is used to estimate badly known aerodynamic parameters that need to be reconstructed. This control strategy allows us to overcome system's modeling errors and the need of expensive sensors. Our objective is to have a complete solution starting from the theory (modelling, observers, control and simulations) and ending with practice (validation and experimental results) 1

\footnotetext{
${ }^{1}$ The reader is invited to visit the "cerfs-volants" section of website [1] to have more details on the activities of Gipsa-lab in this field.
} 
This paper is organized as follows. In section II the aerodynamical model of the wing-based wind power system will be presented. The control strategy will be detailed in section III followed by validation results in simulation (section IV) and in experiment (section V). Finally, after a discussion on the power produced in section VI, the paper will end with conclusions and perspectives in section VII.

\section{AERODYNAMiCAL MODEL}

The tethered wing wind power system proposed in this paper is composed of a ground-based motor that will apply a traction force to a tether connected to a light-weight wing. Length of the tether $r$ is controlled with pitch angle of the wing $\alpha_{u}$ and angle of flight $\theta$ is stabilized with the control of spoilers (see figure 1). The wing's roll angle is mechanically stabilized. Its dynamical model can be given by :

$$
\begin{aligned}
\ddot{\theta} & =\frac{1}{r}\left[-2 \dot{\theta} \dot{r}+\frac{F_{T}}{M}\right] \\
\ddot{r} & =\frac{1}{M+M_{I M}}\left[r \dot{\theta}^{2} M+F_{R}-T\right] \\
\dot{T} & =\beta_{T}\left(u_{T}-T\right) \\
\dot{\alpha}_{u} & =\beta_{a}\left(u_{a}-\alpha_{u}\right)
\end{aligned}
$$

where $r$ is the tether's length from the wing to the motor on the ground, $\theta$ is the angle that the tether makes with respect to the horizon, $M$ is the mass of the wing, $M_{I M}=\frac{I}{R^{2}}$ with $I$ the inertia of the rotor and $R$ the radius of the drum, $T$ is the traction on the rope, $\alpha_{u}$ is the pitch angle of the wing with respect to the ground. Equations 3 and 4 represent the first order dynamic response of actuators used in the experimental plateform to control respectively the traction in the tether and the pitch angle of the wing. Aerodynamical forces $F_{R}$ and $F_{T}$ are respectively the radial and tangential forces acting on the wing due to lift force $L$ and drag force $D$ and are expressed as:

$$
\begin{aligned}
& F_{R}=L \sin \left(\theta-\alpha_{w}\right)+D \cos \left(\theta-\alpha_{w}\right)-P \sin \theta \\
& F_{T}=L \cos \left(\theta-\alpha_{w}\right)-D \sin \left(\theta-\alpha_{w}\right)-P \cos \theta
\end{aligned}
$$

with $\alpha_{w}$ is the wind angle defined later in equation 12 and $P$ is the weight of the wing. Lift and drag forces can be expressed by:

$$
L=0.5 \rho S v_{r}^{2} C_{L}, \quad D=0.5 \rho S v_{r}^{2} C_{D}
$$

where $\rho$ is the air density, $S$ is the wing surface, $v_{r}$ as we will see after is the norm of the apparent wind velocity vector (equation 13). Lift coefficient $C_{L}$ and drag coefficient $C_{D}$ are given in the following equations:

$$
\begin{aligned}
C_{L} & =\frac{\partial C_{L}}{\partial \alpha}\left(\alpha_{w}+\alpha_{u}\right)+C_{L_{0}} \\
C_{D} & =\frac{C_{L}^{2}}{\pi e \lambda}+C_{D_{0}}+\beta_{\theta} u_{\theta}
\end{aligned}
$$

with $C_{L_{0}}, C_{D_{0}}, \beta_{\theta}$ are positive coefficients, $e$ is the Oswald efficiency factor, and $\lambda$ is the aspect ratio. $u_{\theta}$ is the control of the spoilers that modifies the drag of the wing. Note that angle of attack $\alpha$ is equal to the sum of pitch angle $\alpha_{u}$ and angle of apparent wind $\alpha_{w}$ due to the movement of the wing. Horizontal relative air speed $v_{h}$ and vertical airspeed $v_{v}$ depend on the movements of the wing. When the wing is in a stationary position, the variations on $\theta$ and on $r$ are equal to 0 (i.e $\dot{\theta}=\dot{r}=0$ ). One has:

$$
\begin{aligned}
& v_{h}=V+r \dot{\theta} \sin \theta-\dot{r} \cos \theta \\
& v_{v}=r \dot{\theta} \cos \theta+\dot{r} \sin \theta
\end{aligned}
$$

with $V$ is the airspeed with respect to the ground. Using these equations, one obtains angle of wing's apparent wind velocity vector with respect to the horizon $\alpha_{w}$ and its norm $v_{r}$.

$$
\begin{aligned}
\alpha_{w} & =-\arctan \frac{r \dot{\theta} \cos \theta+\dot{r} \sin \theta}{V+r \dot{\theta} \sin \theta-\dot{r} \cos \theta} \\
v_{r} & =\sqrt{(r \dot{\theta} \cos \theta+\dot{r} \sin \theta)^{2}+(V+r \dot{\theta} \sin \theta-\dot{r} \cos \theta)^{2}}
\end{aligned}
$$

In the following sections, the control strategy of each subsystem composing the tethered wing wind power system will be presented.

\section{THE CONTROL STRATEGY}

The control strategy adopted here is to apply an observerbased feedback to the wing-based system in order to force some variables (namely $r$ and the traction force $T$ ) to track a certain periodic profile. The control strategy adopted here is to apply an observer-based feedback to the wing-based system in order to force some variables (namely $r$ and the traction force $T$ ) to track a periodic profile related to the mean power produced. The use of observers is essential since in such a system, model uncertainties must be handled and several variables that cannot be measured must be reconstructed.

\section{A. The control of the angular velocity}

We will first present the control strategy for angular displacement $\theta$ which will be stabilized using spoilers' control $u_{\theta}$. We have experimentally noticed that without spoilers, it is difficult to stabilize angular position $\theta$ because there exist severe oscillations at high angles of attack.Such oscillations have been damped by using spoilers on the wing. Note that the equation (1) can be rewritten in the following condensed form:

$$
\ddot{\theta}=\chi+Q u_{\theta}
$$

where $\chi$ represents the relatively badly known term

$$
\begin{gathered}
Q=-\frac{\rho S v_{r}^{2} \beta_{\theta}}{2 M r} \sin \left(\theta-\alpha_{w}\right) \\
\chi=-\frac{2 \dot{r} \dot{\theta}}{r}+\frac{L \cos \left(\theta-\alpha_{w}\right)-P \cos \theta}{r M} \\
-\frac{\rho S v_{r}^{2}\left(\frac{C_{L}^{2}}{\pi e \lambda}+C_{D_{0}}\right) \sin \left(\theta-\alpha_{w}\right)}{2 r M}
\end{gathered}
$$


This suggests that $\chi$ can be estimated using the following Luenberger estimator based on the sole measurement of $\theta$ :

$$
\begin{aligned}
\hat{\chi} & =\left(\begin{array}{lll}
0 & 0 & 1
\end{array}\right) \hat{X}_{1} \\
\dot{\hat{X}}_{1} & =\left(A_{1}-L_{1} C_{1}\right) \hat{X}_{1}+B_{1} u_{\theta}+L_{1} \theta
\end{aligned}
$$

where the observer's state is $X_{1}=\left[\begin{array}{lll}\theta \dot{\theta} & \chi\end{array}\right]$ and

$$
A_{1}:=\left(\begin{array}{lll}
0 & 1 & 0 \\
0 & 0 & 1 \\
0 & 0 & 0
\end{array}\right) ; B_{1}:=\left(\begin{array}{l}
0 \\
Q \\
0
\end{array}\right) ; C_{1}:=\left(\begin{array}{lll}
1 & 0 & 0
\end{array}\right)
$$

while $L_{1}$ is the observer gain obtained for instance using LQE design. $Q$ is a slow time-varying parameter. This gives the control law given by 15$)-(16)$ together with

$$
u_{\theta}=-\frac{1}{Q}\left[\hat{\chi}+\lambda_{1_{\theta}}\left(\dot{\theta}-\omega_{r e f}\right)+\lambda_{2_{\theta}}\left(\theta-\theta_{\text {ref }}\right)\right]
$$

where $\theta_{\text {ref }}$ and $\omega_{\text {ref }}$ are respectively some desired angle and angular velocity while $\lambda_{1_{\theta}}$ and $\lambda_{2_{\theta}}$ are some design parameters. Note that feedback law (18) only needs the estimation of $\theta, \dot{\theta}$ and $\chi$.

\section{B. The control of traction force $T$}

The periodic traction reference trajectory is given by:

$$
T_{r e f}(t):=T_{0}+\Delta_{T} \sin \left(\frac{2 \pi t}{\tau}\right)
$$

with the condition that $T_{0}-\Delta_{T} \geq T^{\text {min }}$ and $\tau$ is the period. This together with (3) leads to the following feedback law:

$$
u_{T}=T+\frac{1}{\beta_{T}}\left(\dot{T}_{r e f}-\lambda_{2}\left(T-T_{r e f}\right)\right)
$$

with $\lambda_{2}$ a positive control parameter.

\section{The control of radius $r$}

Consider the following reference trajectory on state variable $r:$

$$
r_{r e f}=r_{0}-\Delta_{r} \cdot \dot{T}_{r e f}
$$

The reason behind this choice is that in case of perfect tracking, produced power expressed by $P:=\dot{r} T$ would be positive. This suggests the following reference trajectory on $F_{R}$ involved in (2):

$$
F_{R}^{r e f}=\left(u_{T}-r \dot{\theta}^{2} M\right)+\left(M+M_{I M}\right) h
$$

where $h$ is given by:

$$
h=\ddot{r}_{r e f}-\lambda_{r_{1}}\left(r-r_{r e f}\right)-\lambda_{r_{2}}\left(\dot{r}-\dot{r}_{r e f}\right)
$$

with $\lambda_{r_{1}}$ and $\lambda_{r_{2}}$ are some positive control parameters. Here again based on 22, an estimation $\hat{F}_{R}$ of $F_{R}$ can be obtained based on a Luenberger observer given by:

$$
\begin{aligned}
\dot{\hat{X}}_{2} & =\left(A_{2}-L_{2} C_{2}\right) \hat{X}_{2}+\frac{u_{T}}{M+M_{I M}}+L_{2} r \\
\hat{F}_{R} & =\left(\begin{array}{lll}
0 & 0 & 1
\end{array}\right) \hat{X}_{2}
\end{aligned}
$$

where $X_{2}=\left[\begin{array}{lll}r & \dot{r} & F_{R}\end{array}\right]$ and matrices $A_{2}, C_{2}$ are given by:

$$
\begin{aligned}
A_{2} & :=\left(\begin{array}{ccc}
0 & 1 & 0 \\
\frac{M\left(\omega_{r e f}\right)^{2}}{M+M_{I M}} & 0 & \frac{1}{M+M_{I M}} \\
0 & 0 & 0
\end{array}\right) \\
C_{2} & :=\left(\begin{array}{lll}
1 & 0 & 0
\end{array}\right)
\end{aligned}
$$

and gain matrix $L_{2}$ is obtained using LQE design.

Having estimation $\hat{F}_{R}$ and desired value $F_{R}^{r e f}$, the following feedback can be defined:

$$
\begin{aligned}
u_{a} & =u_{a_{\min }}+\frac{u_{a_{\max }}-u_{a_{\min }}}{2} \\
& +\frac{u_{a_{\max }}-u_{a_{\min }}}{2} \cdot \tanh \left(\gamma\left(F_{R}^{r e f}-\hat{F}_{R}\right)\right)
\end{aligned}
$$

with $\gamma$ is a design variable, $u_{a_{\min }}$ and $u_{a_{\max }}$ are respectively the lower limit and the upper limit of $u_{a}$. Equation 27) together with $(18)$ and $(20)$ completely define the proposed feedback. The complete system (observers, feedback control, and the tethered wing power system) is shown on figure 2 .

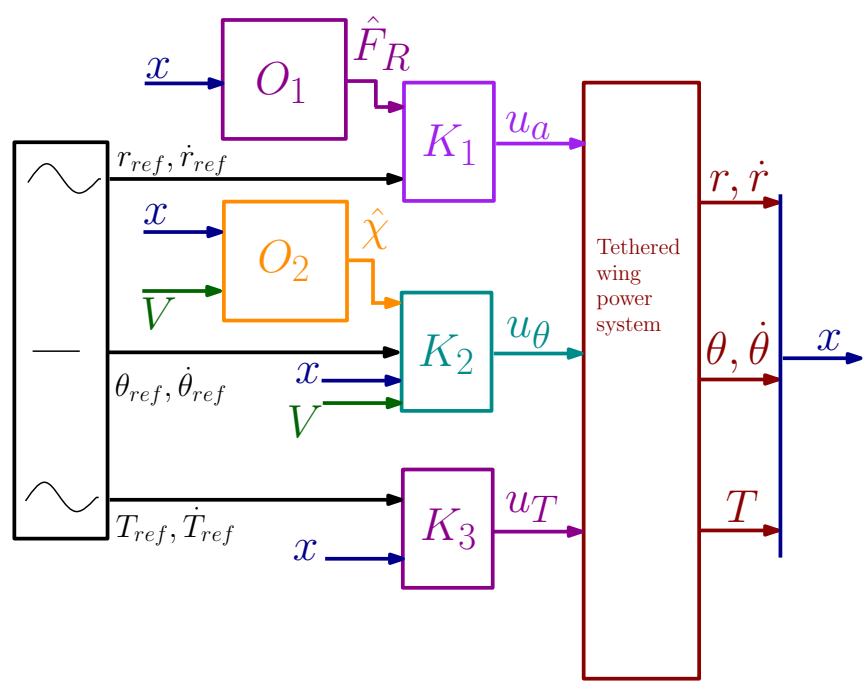

Fig. 2. The complete system: $O_{1}$ and $O_{2}$ are respectively the observers of $F_{R}$ and $\chi . K_{1}, K_{2}$, and $K_{3}$ are respectively the state feedback control of $u_{a}$ (equation 27, $u_{\theta}$ (equation 18, and $u_{T}$ (equation 20.

\section{Simulation Results}

The proposed control strategy is first validated in simulation using values of coefficients of the experimental set-up given in the following table. 


\begin{tabular}{|c|c|c|}
\hline symbol & name & value \\
\hline \hline$M$ & mass & $0.1 \mathrm{Kg}$ \\
\hline$M_{I M}$ & rotor's mass & $0.0481 \mathrm{Kg}$ \\
\hline$\rho$ & air density & $1.225 \mathrm{Kg} / \mathrm{m}^{3}$ \\
\hline$S$ & wing area & $0.1375 \mathrm{~m}^{2}$ \\
\hline$e$ & Oswald's factor & 0.7 \\
\hline$\lambda$ & aspect ratio & 2.5 \\
\hline$\frac{\partial C L}{\partial \alpha}$ & lift derivative w.r.t. $\alpha$ & $0.05 \mathrm{deg}^{-1}$ \\
\hline$C_{D 0}$ & zero lift drag & 0.07 \\
\hline$V$ & mean air speed & $6 \mathrm{~m} / \mathrm{s}$ \\
\hline$\beta_{\theta}$ & drag derivative w.r.t. $u_{\theta}$ & 0.5 \\
\hline$\beta_{a}$ & inverse of the time constant & $100 \mathrm{~s}^{-1}$ \\
\hline$\beta_{T}$ & inverse of time constant & $14.28 \mathrm{~s}^{-1}$ \\
\hline
\end{tabular}

TABLE I

COEFFICIENTS OF THE EXPERIMENTAL SET-UP.

Our objective is to stabilize $\theta$ around $\theta_{\text {ref }}=60^{\circ}$ with a null angular velocity. In addition, the traction force $T$ must follow a periodic reference (equation 19) of a period $\tau=30$ sec. Several combinations of the control parameters $\left(\lambda_{r_{1}}\right.$, $\lambda_{r_{2}}, \lambda_{1_{\theta}}, \lambda_{2_{\theta}}$, and $\gamma$ ) can be used. In fact, this depends whether one wants to focus on the stabilization of the dynamics of $\theta, r$, or on both.

In figure 3 , the evolution of tether's angle $\theta$ and the control of angle of the spoilers $u_{\theta}$ is depicted. One can clearly see the stabilization of angle $\theta$ at the desired value with an angular velocity equals to zero. On figure 4, the variations of tether's length $r$ with respect to the reference trajectory and control $u_{a}$ are plotted. By changing $u_{a}$, the wing arrives to follow the imposed reference on $r$. One can also clearly see the periodic evolution of the traction force $T$ and its control $u_{T}$ on figure 5

\section{EXPERIMENTAL VALIDATION}

In order to validate the proposed control strategy, an experimental set-up has been built in the Gipsa-lab laboratory for testing the proposed wind power system presented in the previous sections. An indoor wind tunnel has been built to
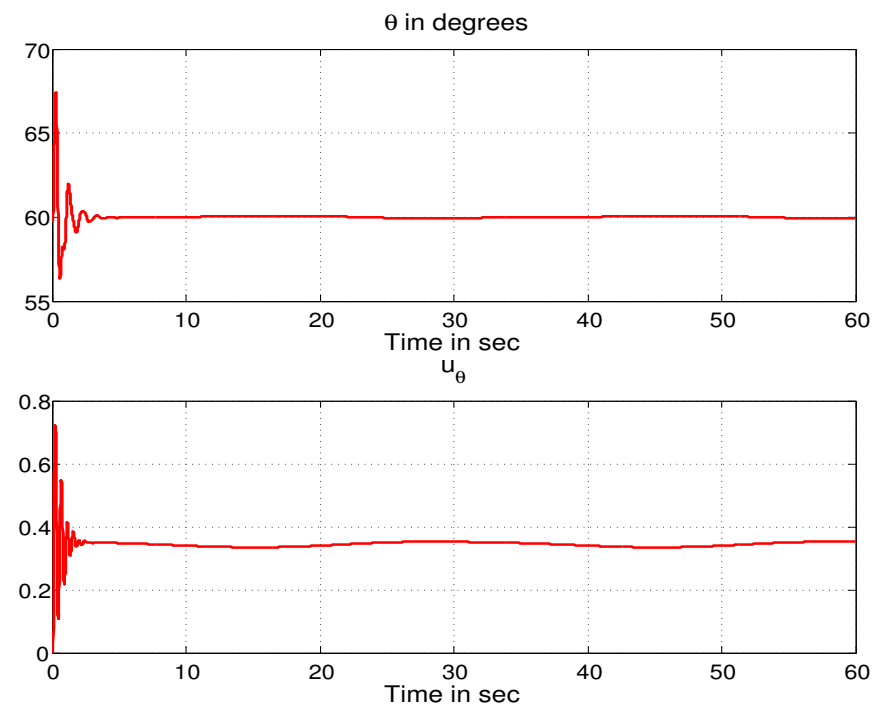

Fig. 3. Simulation: Evolution of the tether's angle $\theta$ and the control $u_{\theta}$. test our prototype independently of the weather conditions (see figure 6). The air flow is produced at speeds up to 12 $\mathrm{m} / \mathrm{s}$. The wind tunnel is composed of 9 brushless motors of $800 \mathrm{~W}$ each distributed on a surface of $1.8 \mathrm{~m}^{2}$. The dynamomotor system is a Maxon 2260L DC 97W driven by a 4 quadrants amplifier Maxon ADS 50/10.

A wing has been built using foam and carbon fiber tubes to increase the rigidity (figure 7). We have chosen a wing profile NACA 0018. The yaw angular position $\psi$ of the wing is controlled using a rudder (figure 7), which is controlled by PID gyroscopic control system FUTABA GY 5020 that stabilizes orientation $\psi$ and angular velocity $\dot{\psi}$. The wing has ailerons driven by servomechanisms which can be deployed to form spoilers. The spoilers are used to vary the drag to introduce damping in the wing displacement. For simplicity, the pitch angle $\alpha_{u}$ is controlled using three strings attached to servomechanisms on the ground. Two tethers are attached to the back tips of the wing and one is attached to the front of the wing. In a future work we will consider controlling the angle of attack with ailerons which is a more realistic. The observer-based feedback controls tested in the simulation part are implemented on the experimental set-up using the xPC target real-time toolbox of Matlab (figure 8). Experimental results are similar to those obtained in the previous
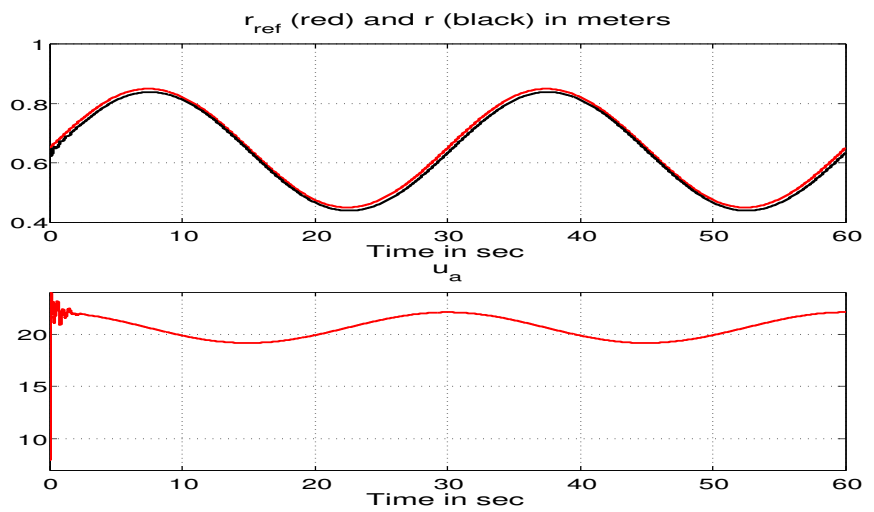

Fig. 4. Simulation: Evolution of the tether's length $r$ with respect to $r_{r e f}$ with the control input $u_{a}$.
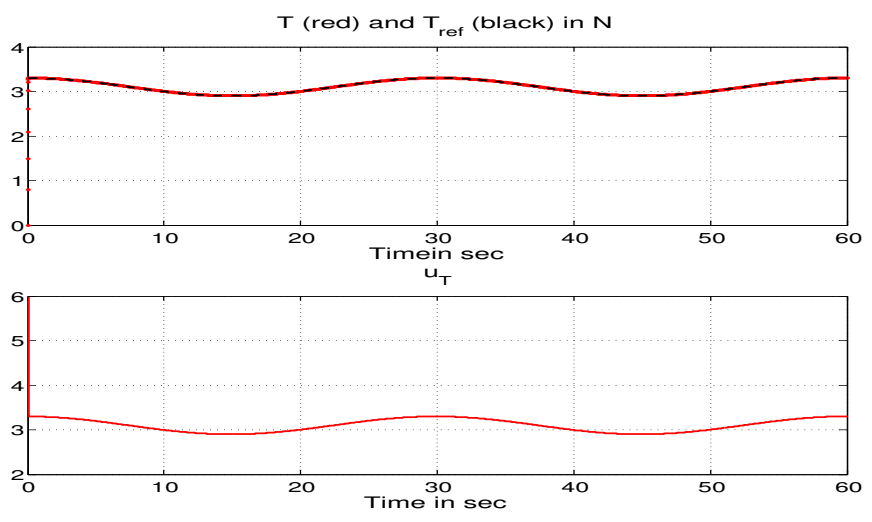

Fig. 5. Simulation: Evolution the traction force $T$ and its reference and the control $u_{T}$. 


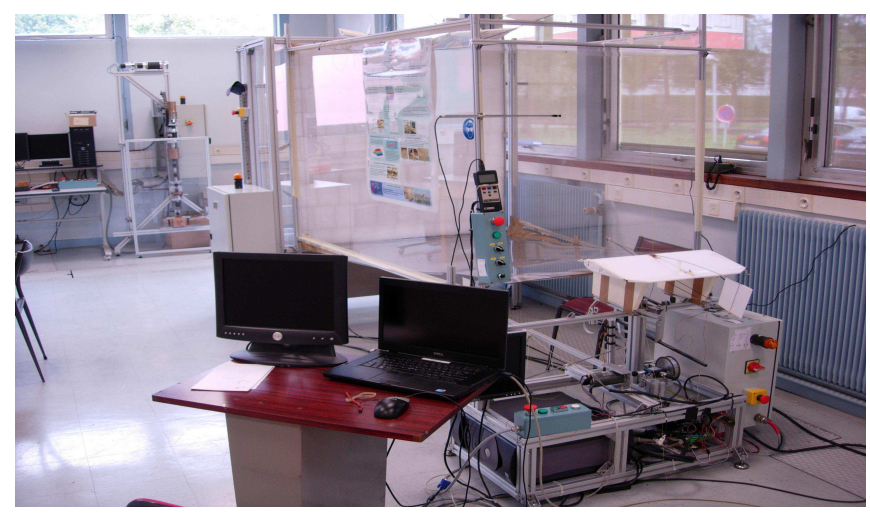

Fig. 6. The Gipsa-lab wind tunnel system, including the $7.2 \mathrm{~kW}$ wind tunnel, the wing, the ground station and the control computer.

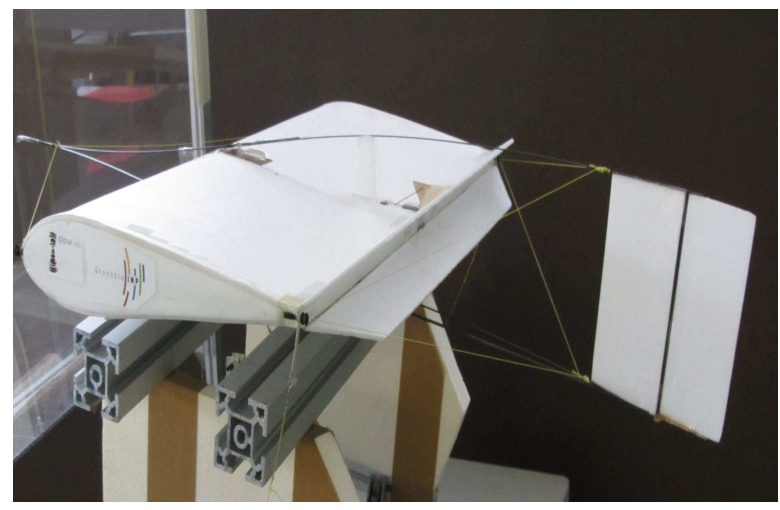

Fig. 7. The wing with the spoilers in a medium drag position and the rudder used for the $\psi$ angle stabilization.

section. One can clearly see on figure 9 the stabilization of the angle $\theta$ at the desired angle ( $65^{\circ}$ for the experiment). The trajectory tracking of measured $r$ and control $u_{a}$ are shown on figure 10 Control $u_{a}$ respects the limits $u_{a_{\text {min }}}=8^{\circ}$ and $u_{a^{\max }}=22^{\circ}$. Traction force $T$ applied to the experimental set-up is shown on figure 11 . The control of the traction force was done by the Maxon amplifier in torque control mode.

\section{DISCUSSION ON THE POWER PRODUCED}

As mentioned in the introduction, the system presented in this paper is a kite-based wind power system. The power produced using the control developed in section [V] and in section $\mathrm{V}$ is shown respectively on figure 12 and figure 13 . The mean power is positive although it is not big because of two reasons:

- Our main concern is to control the trajectory tracking by developing control laws robust with respect to modeling errors without the need of expensive sensors to measure aerodynamical forces and variables badly known.

- The small size of the experimental set-up. Simulations show that the wing's surface, the wind speed, the limits on $r$, and the reference trajectory play an important role in modifying the produced power. Moreover, the small size makes difficult to have crosswind trajectories that lead to better performances in terms of produced power.

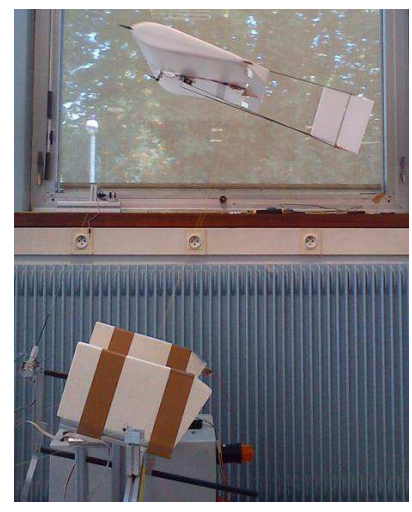

Fig. 8. Flight test for the wind power system in the GIPSA wind tunnel.

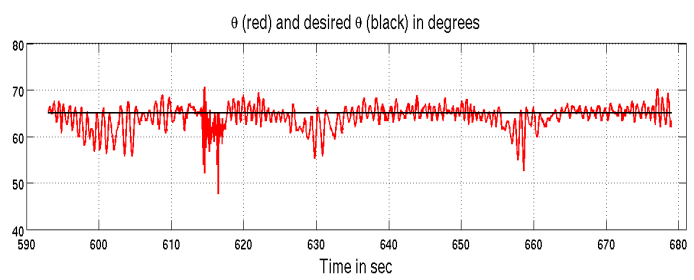

$u_{\mathrm{B}}$

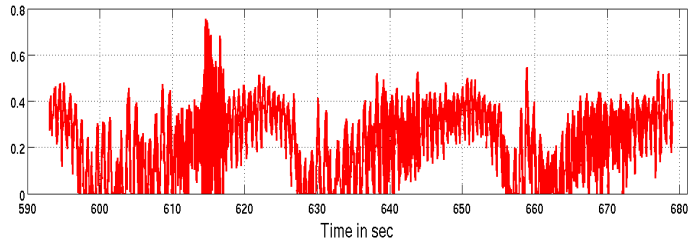

Fig. 9. Real-time experiment: Evolution of the tether's angle $\theta$ and the control $u_{\theta}$.

\section{CONCLUSIONS AND PERSPECTIVES}

\section{A. Conclusion}

In this paper we have studied a wind power generation system mainly composed of a wing attached to a dynamo with a tether. The wing subject to airflow generates a lift force which drives the dynamo on the ground to generate power. We have focused on such a configuration because it is less expensive than current wind power systems and could be used in rural areas to go to high altitudes without infrastructure. We have presented an aerodynamical model of the system. We have also proposed an observer-based control strategy to stabilize the wing's flight angle and to track a periodic reference on the tether's length. An indoor experimental set-up has been built including a wind tunnel, a wing with spoilers and a control system for the pitch angle. Both simulation and experimental results show promising results on the generated power.

\section{B. Perspectives}

For a future work, an observer of the wind speed (supposed to be known in the actual paper) will be designed. Another option is to design a nonlinear observer based on the measurement of $\theta$ and $u_{\theta}$ to estimate the $Q$ term of equation (14) 


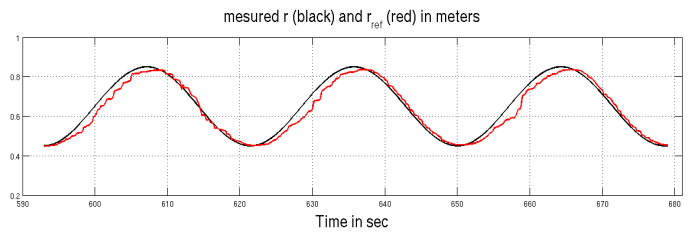

$u_{a}$

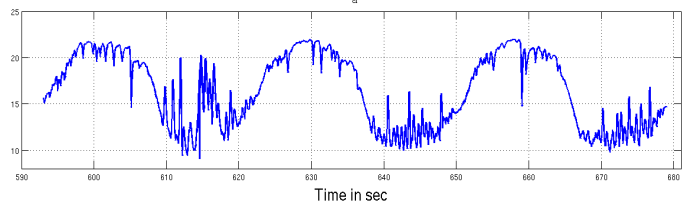

Fig. 10. Real-time experiment: Evolution of the tether's length $r$ with respect to $r_{r e f}$ with the control input $u_{a} . r_{r e f}$ and $T_{r e f}$ are chosen in order to have a positive produced power.

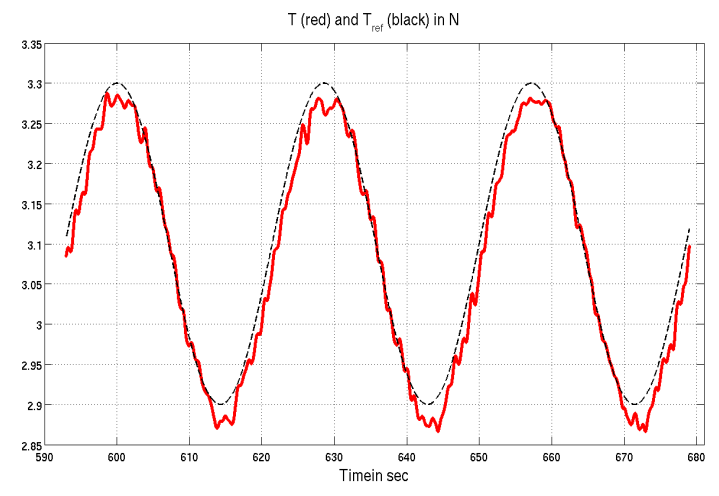

Fig. 11. Real-time experiment: Evolution the traction force $T$ and its reference. The maximum and minimum values are determined by the limits of $\alpha_{u}$ of the experimental set-up.

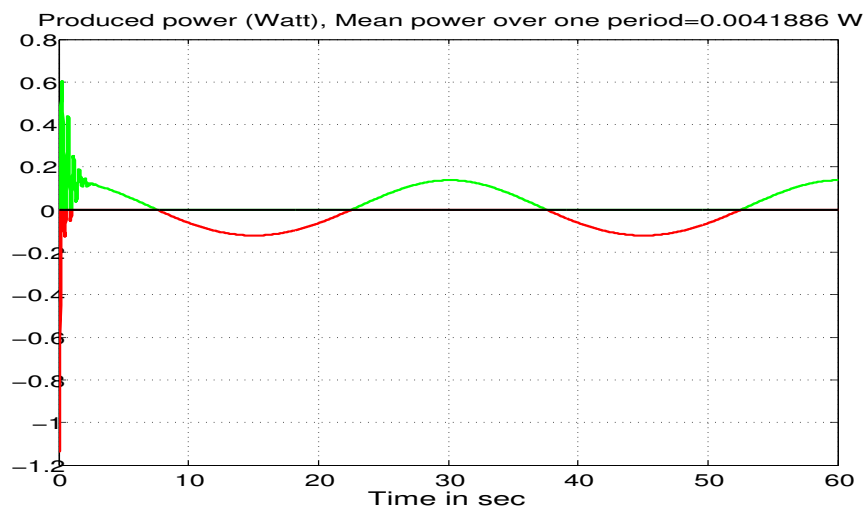

Fig. 12. The power produced in the simulation. The mean power over one period (between $22 \mathrm{sec}$ and $52 \mathrm{sec}$ ) is equal to $0.0041886 \mathrm{~W}$.

to overpass the need of the exact value of wind speed. Further study will be done to obtain three dimensional optimal cycles that maximizes the generated power and the possibility of using the observer-based control approach for tracking these optimal trajectories. The choice of the cycle's period and the slope of the reference signal plays an important role in this direction. The slope in the production phase (when the

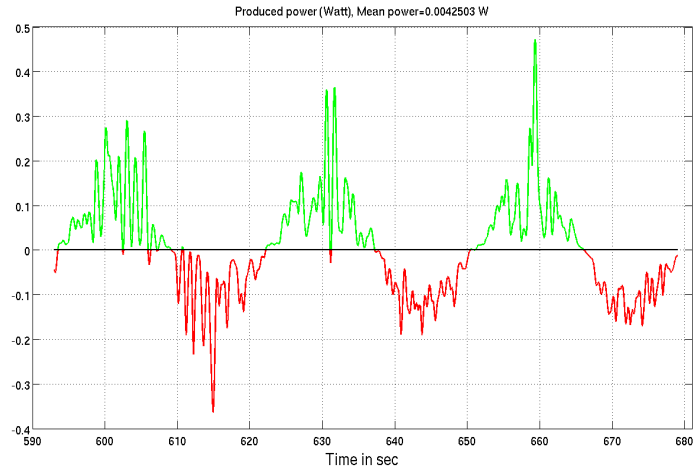

Fig. 13. The power produced in the real time experiment. The mean power over one period is equal to $0.0042503 \mathrm{~W}$.

wing pulls up the tether) must be less than the slope in the consumption phase (when the wing is pulled by the motor) in order to increase the total result.

\section{ACKNOWLEDGMENT}

The authors would like to thank the technical staff of Gipsa-lab who provided an important technical support in the construction of the experimental set-up.

\section{REFERENCES}

[1] http://www.gipsa-lab.grenoble-inp.fr/recherche/plates-formes.php.

[2] M. Ahmed, A. Hably, and S. Bacha. Power maximization of a closedorbit kite generator system. In 50th Conference on Decision and Control and European Control Conference (IEEE CDC-ECC), 2011.

[3] M. Ahmed, A. Hably, and S. Bacha. High altitude wind power systems: A survey on power kites. In The International conference on electrical machines, 2012.

[4] J.H. BAAYEN. Automatic trajectory tracking control of kites. PhD thesis, Delft University of Technology, 2011.

[5] M. Canale et al. High altitude wind energy generation using controlled power kites. IEEE Transactions On Control Systems Technology, 18(2):279 - 293, 2010.

[6] M. Canale, L.Fagiano, and M.Milanese. Kitegen: A revolution in wind energy generation. Energy, 34:355-361, 2009.

[7] A. Furey and I. Harvey. Evolution of neural networks for active control of tethered airfoils. Advances in Artificial Life, pages 746-755, 2007.

[8] http://www.jobyenergy.com/.

[9] http://www.makanipower.com/.

[10] A. Ilzhofer, B. Houska, and M. Diehl. Nonlinear MPC of kites under varying wind conditions for a new class of large-scale wind power generators. International Journal Of Robust And Nonlinear Control, 17:1590-1599, 2007.

[11] C. Novara, L. Fagiano, and M. Milanese. Direct data-driven inverse control of a power kite for high altitude wind energy conversion. In IEEE International Conference on Control Applications (CCA), pages 240-245, 2011.

[12] A.R. Podgaets and W.J. Ockels. Robust control of laddermill wind energy system. In Proceedings of the Wind Power Shanghai Conference, 2007.

[13] P. Williams, B. Lansdorp, and W. Ockels. Optimal cross-wind towing and power generation with tethered kites. In AIAA Guidance, Navigation and Control Conference and Exhibit, 2007. 